\title{
ЦЕНООБРАЗОВАНИЕ В ГОСУДАРСТВЕННЫХ ЗАКУПКАХ
}

\author{
Добротина Олеся Викторовна \\ Директор консалтинговой фирмы Тендэксперт \\ (ООО «Тендэксперт»)
}

\begin{abstract}
Аннотация: процесс ценообразования в государственных закупках является для заказчиков одним из самых важных этапов подготовки и проведения закупочных процедур. От него зависит эффективность использованию бюджетных средств и качество поставляемых товаров, выполненных работ и оказанных услуг. Законодательством предусмотрено пять основных методов расчета и обоснования цены в государственных закупках, особенности которых описаны в данной статье.
\end{abstract}

Ключевые слова: цена, начальная (максимальная) цена контракта (НМЦК), заказчик, закупка, контракт.

\section{PRICING OF GOVERNMENT CONTRACTS}

\section{Dobrotina Olesya Viktorovna}

\begin{abstract}
: the process of pricing in government contracts is one of the most important stages of preparation and implementation of procurement procedures for customers. It determines the efficiency of using budget funds and the quality of goods delivered, works performed and services rendered. The legislation provides for five main methods of calculating and justifying prices in public procurement, the features of which are described in this article.
\end{abstract}

Key words: price, initial (maximum) contract price, customer, purchase, contract.

Одним из основных принципов осуществления закупочной деятельности в рамках Федерального закона от 05.04.2013 N 44-Ф3 "О контрактной системе в сфере закупок товаров, работ, услуг для обеспечения государственных и муниципальных нужд" (далее - 44-Ф3) является эффективность осуществления закупок. Основной задачей, которая стоит перед Заказчиком является обеспечение государственной или муниципальной потребности с наибольшей экономической эффективностью. Этот принцип реализуется на этапе формирования начальной максимальной цены контракта и цены контракта, 
заключаемого с единственным поставщиком (подрядчиком, исполнителем) (далее - НМЦК).

Процесс ценообразования является для заказчика одним из самых важных этапов в процессе подготовки и проведения закупочной процедуры.

В случае неверного расчета и занижения НМЦК есть вероятность, что закупка будет признана несостоявшейся, так как никто из поставщиков не будет выполнять условия контракта себе в убыток или же заказчик сможет нарваться на недобросовестного поставщика, который выйдет на закупку, но впоследствии не выполнит условия контракта.

При завышении НМЦК заказчика могут привлечь к ответственности за неэффективное расходование бюджетных средств.

Поэтому заказчики должны с предельной внимательностью и точностью подходить к процессу формирования и обоснования НМЦК.

Ценообразование в государственных закупках регламентируется 22 статьей 44-Ф3 и приказом Министерства экономического развития РФ от 2 октября 2013 г. N 567 "Об утверждении Методических рекомендаций по применению методов определения начальной (максимальной) цены контракта, цены контракта, заключаемого с единственным поставщиком (подрядчиком, исполнителем)".

Определение НМЦК производится при формировании плана-графика закупки, подготовке извещения об осуществлении закупки, документации о закупке. Результат определения НМЦК отражается в указанных документах.

Существует пять основных методов расчета и обоснования цены в государственных закупках:

1. Метод сопоставимых рыночных цен (анализ рынка).

Данный метод означает, что заказчику для формирования и обоснования НМЦК необходимо получить информацию о рыночных ценах идентичных товаров, работ или услуг, а при их отсутствии однородных товаров, работ или услуг.

В целях применения данного метода могут использоваться следующие источники информации:

- общедоступные сведения о рыночных ценах товаров, работ, услуг;

- информация о ценах, полученная по запросу заказчика у поставщиков, производящих поставки идентичных товаров, работ, услуг, или при их отсутствии однородных товаров, работ, услуг;

- сведения, полученные по итогам размещения запросов цен товаров, работ, услуг в ЕИС. 
При использовании данного метода важно отличать идентичную продукцию от однородной. Под идентичной понимаются товары, работы, услуги имеющие одинаковые характерные признаки, но при этом могут иметь отличия во внешнем виде. Такие товары чаще всего производят организации с сопоставимой квалификацией, которые используют аналогичные методики и технологии. Однородные товары - это товары со сходными характеристиками и состоящие их схожих компонентов, что позволяет им быть коммерчески заменяемыми.

Основная проблема, которая возникает при использовании данного метода заключается в том, что 44-Ф3, а также методические рекомендации по применению методов определения НМЦК, цены контракта, заключаемого с единственным поставщиком (подрядчиком, исполнителем), утвержденные Министерством экономического развития Российской Федерации не дают более подробных разъяснений по применению понятий идентичности и однородности. Соответственно, ответственность за использование таких коммерческих предложений полностью ложится на заказчика с вытекающими возможными ошибками.

Какие еще могут возникнуть ошибки при применении данного метода:

- использование при расчете цены не исполненных или исполненных ненадлежащим образом контрактов;

- использование цен неактуальных каталогов и прайс-листов;

- запрос коммерческих предложений у аффилированных компаний;

- запрос коммерческих предложений у неблагонадежных компаний;

- неточное описание предмета закупки при сборе информации о ценах и др.

При применении данного метода расчета НМЦК важно учитывать такое понятие, как коэффициент вариации. Под коэффициентом вариации понимается отклонение коммерческого предложения от среднего значения цены. В случае если данный коэффициент превышает 33\%. Это свидетельствует о том, что полученные данные неоднородны и при расчете НМЦК не допускается их использование и необходимо повторно провести анализ рынка.

Данный метод является приоритетным для определения и обоснования цены контракта. Так как при осуществлении госзакупок особую важность играет соблюдение законодательства о защите конкуренции, любой заказчик в первую очередь будет рассматривать данный метод для расчета. Если окажется, что его применить невозможно в данных условиях, то он рассмотрит иные 
методы расчета НМЦК и цены контракта, заключаемого с единственным поставщиком (подрядчиком, исполнителем).

2. Нормативный метод.

Основная цель заключается в установлении норм закупок продукции для государственных и муниципальных нужд, позволяющие обеспечить данные нужды, но не приводящие к закупкам, которые имеют избыточные потребительские свойства или являются предметами роскоши в соответствии с законодательством РФ. Соответственно органами государственной власти устанавливаются и нормативные затраты на данные потребности, которые заказчик не вправе превышать.

Нормы закупок разработаны на такие товары, как автотранспортные средства, вычислительная техника, программное обеспечение, мебель для офисов, услуги такси, услуги по аренде автомобилей и др.

3. Тарифный метод.

Данный метод применяется заказчиком в случае, если цены на закупаемую продукцию подлежат государственному регулированию или установлены муниципальными правовыми актами. В данном случае НМЦК и цена контракта, заключаемого с единственным поставщиком (подрядчиком, исполнителем) определяется по регулируемым тарифам на товары, работы и услуги.

В данном случае перед заказчиком стоит одна основная задача представить нормативный акт, в котором указано, что цена на закупаемую продукцию регулируется государством.

Данный метод применяется в основном при закупке таких услуг, как газоснабжение, теплоснабжение, электроснабжение, водоснабжение и водоотведение, услуги общедоступной электросвязи, услуги общедоступной почтовой связи, услуг страхования, поставка лекарственных средств и др.

4. Проектно-сметный метод.

Сфера применения данного метода строго ограничена п. 9 ст. 22 44-Ф3, что обусловлено спецификой предмета закупаемой продукции.

В частности, данный метод применяется в следующих случаях:

- строительство, реконструкция, капитальный ремонт, снос объекта капитального строительства;

- проведение работ по сохранению объектов культурного наследия, за исключением научно-методического руководства, технического и авторского надзора;

- текущий ремонт зданий, строений, сооружений. 
Перечень, объемы и стоимость учитываемых при определении НМЦК проектно-сметным методом работ и услуг устанавливаются заказчиком в соответствии с утвержденной проектной документацией по объекту закупки.

Проектно-сметная документация обосновывает целесообразность и возможность реализовать данный проект. Она содержит материалы в текстовом формате, в виде схем и определяет архитектурные, функциональнотехнологические, конструктивные и инженерно-технические решения для обеспечения строительства, реконструкции или ремонта объектов.

В целях предотвращения строительства объектов, возведение и последующая эксплуатация которых противоречит нормам, установленным законодательством, проектные документы подлежат обязательной государственной экспертизе.

5. Затратный метод.

Этот метод является самым спорным и противоречивым. Он применяется в основном, когда заказчику необходимо изготовить какой-то особенный индивидуальный товар или товар с индивидуальной составляющей, какого не существует на рынке. Также данный метод может применяться при закупке научно-исследовательских и опытно-конструкторских работах.

Чтобы у заказчика возникла возможность применения данного метода ему для начала необходимо указать невозможность применения остальных четырех методов. Для этого придется обосновать, что коммерческих предложений на данную продукцию не поступало, так как она является индивидуальной; закупка данной продукции не нормируется государством; цена на данную продукцию не подлежит государственному регулированию в соответствии с законодательством РФ и проектная документация на закупку отсутствует.

Плюсом для заказчика в применении данного метода является то, что калькуляция прибыли и затрат осуществляется непосредственно самим заказчиком это может помочь избежать накручивания цены со стороны поставщика как при подаче коммерческого предложения.

Минусом же для заказчика будет являться то, что для обоснования данных затрат и прибыли ему необходимо будет проанализировать аналогичные контракты, размещенные в единой информационной системе, провести анализ рынка, что в данной ситуации будет очень сложно для заказчика.

Не всегда калькуляция, произведенная заказчиком, полностью отражает специфику выполнения работ и расчет поставщика на выполнение данных 
работ. Неверно учтенные расходы и прибыль поставщика и некорректно обоснованная цена могут повлечь наложение административного штрафа.

Обоснование цены является для государственных и муниципальных заказчиков важным и ответственным процессом, так как он напрямую влияет на результат проведения закупки, на результат поставляемой продукции, выполненных работ и оказанных услуг в рамках заключенного контракта, а при допущении ошибок может повлечь административную ответственность для заказчика.

Основные ошибки, которые могут быть допущены заказчиками при формировании и обосновании цены заключаются в следующем:

- заказчик может выбрать неверный метод для расчета НМЦК;

- заказчик может неверно собрать данные о ценах, неправильно составить техническое задание для запроса коммерческих предложений;

- цены получены от индивидуальных предпринимателей и юридических лиц, находящихся в реестре недобросовестных поставщиков;

- формирование и обоснование цены необходимо осуществить еще на этапе планирования закупки и в случае изменения НМЦК необходимо внесение изменений в план-график и др.

Основной причиной сложностей и ошибок, допускаемых на этапе формирования цены контракта, является недостаточное нормативное регулирование данного процесса. Так как статья 22 44-Ф3 дает лишь общие понятия о методах и порядке формирования цены контракта, а методические рекомендации по применению методов определения начальной (максимальной) цены контракта, цены контракта, заключаемого с единственным поставщиком (подрядчиком, исполнителем), утвержденные Министерством экономического развития РФ, носят не обязательный, а лишь рекомендательный характер.

При проведении государственных закупок участники предлагают свои цены в отношении закупаемой продукции, которые должны быть ниже НМЦК, за исключение тарифного метода. Победителем становится участник, который сделал наилучшие предложение, в том числе по цене.

Максимальную цену определяет государственный и муниципальный заказчик. Цену контракта определяют участники закупки.

По данным официального сайта Единой информационной системы в сфере закупок (https://zakupki.gov.ru/) за 2019 год было проведено 2,96 млн. закупок с общей суммой начальным максимальных цен контрактов 9 806,53 млрд. рублей. По итогам закупок было заключено контрактов на сумму 8 252,30 
млрд. рублей. Экономия бюджетных средств по результатам осуществленных закупок составила $15,85 \%$.

Ценообразование в сфере государственных закупок строго регулируется нормативными актами, с целью избежать завышения или занижения цен, сформированных заказчиком при проведении закупочных процедур. Контролирующие органы строго следят за правильностью и обоснованностью формирования НМЦК, и заказчик всегда должен быть готов аргументировать полученную НМЦК и метод, используемый при получении данной цены. В противном случае это может привести к отмене и повторному проведению закупки с прохождением всех этапов подготовки процедуры по новой или же к привлечению заказчика к административной ответственности за несоблюдение порядка или формы обоснования НМЦК.

\section{Список литературы}

1. Закон о контрактной системе (закон о госзакупках). Федеральный закон от 5 апреля 2013 г. N 44-Ф3 "О контрактной системе в сфере закупок товаров, работ, услуг для обеспечения государственных и муниципальных нужд" (с изменениями и дополнениями);

2. Приказ Министерства экономического развития РФ от 2 октября 2013 г. N 567 "Об утверждении Методических рекомендаций по применению методов определения начальной (максимальной) цены контракта, цены контракта, заключаемого с единственным поставщиком (подрядчиком, исполнителем)".

О.В. Добротина 